\title{
Emancipating (im)politeness research and increasing its impact
}

\author{
Wei Ren \\ Beihang University, Beijing \\ weiren@buaa.edu.cn
}

\begin{abstract}
This paper explores how the authors to the papers in this special issue of Acta Linguistica Academica (2019/2) understand the performance and evaluation of (im)politeness in various types of Chinese data across different contexts. The paper looks at the long-debated issue of universalism and particularism in (im)politeness research, since interaction takes place within different sociocultural systems, in different situational settings, at different interactive contexts, and with different interlocutors. The paper also brings forward the necessity to enhance the impact of Chinese (im)politeness research.
\end{abstract}

Keywords: (im)politeness; Chinese; emancipatory pragmatics; impact

\section{Introduction}

Politeness has attracted an enormous amount of research attention in pragmatics since the 1970s. Later, after approximately two decades, impoliteness has also become an oft-investigated phenomenon in linguistics research (e.g., Bousfield 2008; Culpeper 1996; 2011; Dynel 2015). In this postscript, for the reasons of brevity and space, I will use (im)politeness to denote politeness and impoliteness.

Nowadays, most (im)politeness researchers have reached a consensus that it is not the linguistic form per se invariably carrying (im)politeness across contexts. Instead, it is the participant's evaluation of the interaction that is polite or impolite (Eelen 2001; Kádár \& Haugh 2013; Locher \& Watts 2005; Mills 2003; Watts 2003). For an overview of linguistic (im)politeness research, refer to Kádár's (2019) introduction. In addition, polite and impolite cannot cover all the judgement of an individual's utterance or social behavior. They just represent two ends of an evaluative continuum. The boundaries between the perceptions of the evaluative concepts such as polite or impolite, as Watts (2005) reminds us, vary considerably from speaker to speaker, and from community of practice to community of practice. Note that Watts (2005) proposes a marked behavior 'overpolite' 
to indicate the other end of the evaluative continuum opposite to impolite. Therefore, there are two important questions to consider for linguistic (im)politeness research:

- To what extent do universal and cultural aspects of linguistic (im)politeness overlap?

- How do theoretical approaches to linguistic (im)politeness benefit from examinations of (im)politeness practices in a particular language/culture and vice versa?

The aim of this postscript is not to offer summaries of the papers, neither is it to offer a judgement about each contribution. Instead, it discusses the papers with respect to the thorny issue of universalism and particularism, or generality and specificity, long investigated in (im)politeness studies. Before the conclusion, it also discusses how we can increase the impact of Chinese (im)politeness research within the emancipatory perspective.

\section{Emancipating (im)politeness research}

Pragmatics still privileges a western notion of what (im)politeness is. Many researchers construct their (im)politeness models and theories as universally applicable. However, Hanks $(2012,564)$ notes that, 'as linguistic systems are functionally driven resources for interaction, they too may be motivated by social relations and values'. Therefore, to understand the (im)politeness practice in a certain language and culture, researchers need to investigate it in the social-culturally situated context of interpersonal communication. Indeed, there are increasing numbers of empirical investigations into (e.g., Fukushima 2016; Haugh 2016; He \& Ren 2016; Kim 2014; Panpothong \& Phakdeephasook 2014) and theoretical discussions on (e.g., Hanks, Ide and Katagiri 2009; Spencer-Oatey \& Kádár 2016) (im)politeness practices in particular languages other than English, rather than simply perceiving them as local applications of some universal phenomena. Figure 1 presents an overly simplified model of affordances of and constraints on interpersonal interactions.

As the diagram indicates, people interact based on their pragmatic competences, which can be defined as 'the ability to use language effectively in order to achieve a specific purpose and to understand language in context' (Thomas 1983, 92), though I would add 'appropriately' to the definition. It has to be admitted that individuals' pragmatic competences 


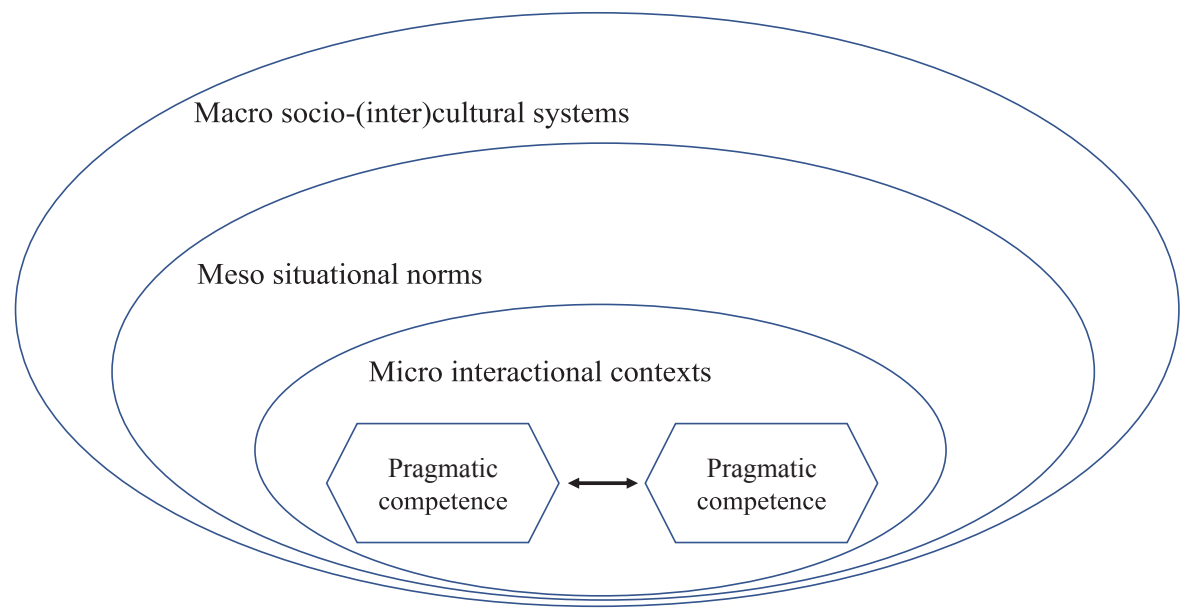

Figure 1: Layers of affordance of and constraints on interpersonal interaction

are not identical, as represented in different shapes in the diagram. In addition to their own pragmatic competences, the interactants also need to pay attention to the immediate interactional contexts (the micro level) and the situational communicative norms and/or conventions (the meso level). At the macro level, the interactants should stick to the sociocultural systems they belong to, respectively. Therefore, there is a crucial question for interactants to consider, particularly in intercultural communication: whose norms or systems should interactants adjust their performances to and evaluate an utterance or a practice against? Cross-cultural pragmatics has revealed that people from different cultures perform and perceive (im)politeness differently (Blum-Kulka et al. 1989; Chang \& Haugh 2012; Culpeper et al. 2010). Variational pragmatics studies have also observed intralingual differences in native speakers' pragmatic performance across region, gender, and age (Barron 2017; Barron \& Schneider 2009; Dinkin 2018; Lin et al. 2012; Ren 2018c; Ren et al. 2013; Schneider \& Barron 2008). In addition, preceding studies have found that in lingua franca communication people tend to focus on clarity (Mauranen 2006; Ren 2016; 2018b) rather than (im)politeness traditionally constructed in (im)politeness theories, particularly in the first wave approaches (see Kádár 2019).

To liberate pragmatics from Euro-American languages and ways of interacting, it is not enough for emancipatory pragmatics to just expand investigations into a wider range of languages. It needs to discover 
a useful perspective to understand a culture, without having to assume that the perspective is only applicable to the culture. As Panpothong and Phakdeephasook (2014) state, the wide use of the Thai expression maipen-rai is difficult to analyze and to understand for those who study Thai as a foreign language, because the phrase can be used functionally as a response to apologizing and thanking, a refusal strategy to an offer, a remark of consolation, and a strategy to terminate verbal conflict. However, despite the different interactional functions, the core meaning of mai-penrai is closely related to the Buddhist concept of Tri Laksana (the three characteristics of existence), according to which everything is impermanent and so anything is not substantial. Thus, the Buddhist ideology helps to achieve a deep appreciation of the Thai linguistic practices. Similarly, in the present special issue, Lee compares the uses of first-person pronominal forms in two historical literary works and explores the reason behind the co-existence of the four first-person pronouns. Unlike the rich literature investigating second-person pronouns in European languages, Lee's study on classical Chinese sheds light on the largely ignored first-person pronouns and reveals that pronominal forms provide insights into the person who uses them and the context in which they are used. This work is illuminating and makes us wonder whether the disappearance of the three Chinese first-person pronouns ( $w u, y u$, and zhen) relates to the simplification of social relations between interlocutors, a tendency also discussed in address terms in Chinese (He \& Ren 2016). Focusing on the Chinese political advice, Liu and Shi (2019) demonstrate the difficulty to disentangle the behavioral types of public advice. They argue that Chinese political advice is genre or practice designed. Although it takes place in the context of international events and intercultural encounters, it is better perceived as a national public discourse. The paper thus exemplifies the necessity to examine the similarities and differences of a speech act in public vs. private contexts (cf. pulic apologies in Page 2014).

Furthermore, emancipatory pragmatics may also develop frameworks paying close attention to other ways of interacting (Hanks et al. 2009; Mey 2012). For example, Kim (2014) reveals that self-deprecating language used in conversation, in which speakers lower or humble themselves toward their addressees, may be used to create or maintain relationships between speakers involved. It is problematic to interpret the self-deprecation practices in Korean and Japanese under the Western culture-based frameworks. Likewise, Chen (2019) proposes 'family culture' as an ideological construct to understand and analyze the discursive (im)politeness practices in contemporary China. He demonstrates that Chinese politeness is better in- 
terpreted in a familial nexus, often projected above individuals in many existing politeness models. Consequently, he formulates a set of maxims to account for discursive practices of Chinese politeness. Kádár and Zhang (2019) also develop a model of alignment to analyze public monologues in Chinese. The authors demonstrate that Chinese public monologues cannot be analyzed under (im)politeness in the interpersonal sense. Rather, they are used beyond the interpersonal agenda as part of a discursive engagement to form alignments with the public.

However, we cannot end emancipatory (im)politeness missions at merely describing and analyzing Chinese practices. We should move a step further to testify the perspectives and constructs developed. In addition, we need to explore the extent to which the Chinese (im)politeness practice, or (im)politeness practice in any language/culture, is specific. To what extent is the local specific concept and practice applicable or commensurable to other local concepts and practices? That is, studies should build on each other to investigate the degree of specificity vs. generality of a local concept to frame Chinese (im)politeness research within the emancipatory paradigm. For example, to what extent is the (im)politeness practice in family-culture (Chen 2019) commensurable to that in clan-culture languages? To what extent is political advice in Chinese (Liu \& Shi 2019) comparable to that in other languages/cultures? Does the disappearance of the three Chinese first-person pronouns (Lee 2019) result from similar sociopragmatic influences that also lead to the disappearance of the second-person pronoun 'thou' in English or changes of pronouns in other languages? This further step not only can advance our understanding of linguistic (im)politeness but also point out future directions of Chinese emancipatory pragmatics.

\section{Increase the impact of Chinese (im)politeness research}

This is a two-fold question: a) to increase the impact of (im)politeness research based on Chinese data within the field of (im)politeness and pragmatics research, and more broadly in linguistics and other academic disciplines; b) to disseminate the academic findings and apply them to enhance existing or future models of policies and practices of interactional behavior in institutional settings (Bousfield 2018).

On the one hand, as stated above, Chinese (im)politeness research should not be satisfied with investigating (im)politeness practices and describing the lingua-cultural phenomena in Chinese concepts and terms. The researchers may expand their interest to apply their emancipatory 
pragmatics findings to practices in other linguistic and socio-cultural systems (at the macro level), by comparing different interactional contexts (at the micro level) and different situational norms (at the meso level). (Im)politeness and pragmatics research findings and models can also complement and/or supplement models and theories in other linguistic branches and disciplines. For example, Lee's (2019) empirical observation of first-person pronouns in classical Chinese provides illuminating insights into lexico-grammatical studies traditionally grounded in syntax. The same can be argued to Zhu's (2019) investigation into topic switching in Chinese conversations.

On the other hand, (im)politeness and pragmatics research, not restricted to studies on Chinese data, should try to disseminate findings to the society (Bousfield 2018; Mey 2012). By society, I mean 'members of society outside of academia who may not know or recognize' what pragmatists or linguists do as being relevant or useful to them (Bousfield 2018, 290). The contributions in the present special issue, particularly the empirical investigations into public political advice (Liu \& Shi 2019) and public political monologues (Kádár \& Zhang 2019), can benefit the existing practices and policies in the related occupational, legal, social and diplomatic institutions.

In addition to research topics and findings, improvements to how pragmatists and (im)politeness researchers collect and analyze data can often lead to more persuasive tests of theories, models or constructs, and more convincing applications in the real world (Marsden et al. 2016). The papers in this special issue base their arguments on well-designed empirical investigations into comprehensively and situationally contextualized examples, including face-to-face interaction ( $\mathrm{Zhu}$ ), open-access video-recordings of multi-party interaction (Kádár \& Ning), literary works (Chen; Lee), and political discourse (speeches in Liu and Shi; monologues in Kádár \& Zhang). The papers demonstrate the advantage of examining various types of data, including oral and written data, as well as data disseminated online. Also, detailed descriptions of data collection and analyses enhance the rigor of the research and the validity of the interpretation in the papers.

All the studies in this issue have pointed out the importance to study linguistic forms/practices in Chinese that are framed in different sociocultural systems from their western counterparts (the macro layer in Figure 1) (Kim 2014; Panpothong \& Phakdeephasook 2014). For example, Kádár and Ning (2019) showcase that in the contemporary Chinese society there still exists gendered ideologies deeply rooted in Confucian philosophy. Zhu (2019) examines unexpected topic switching in Mandarin Chinese 
conversations, which is constrained by context and may be perceived as appropriate by the participants. In addition, the studies examined linguistic units at various analysis levels (Jucker 2018), from units smaller than utterances (e.g., pronouns in Lee 2019) to units larger than utterances (e.g., monologues in Kádár \& Zhang 2019). Since language is always dialogic (Bakhtin 1981), it is illuminating to explore the influence of the participation status in (im)politeness and alignment in the Chinese public political monologues (Kádár \& Zhang 2019). Another issue worth investigation is how much of an overlap in these features/practices do they share with respect to (im)politeness across different genres and/or in intercultural encounters. Advancing these methodological practices will increase the impact of (im)politeness research on other related disciplines.

\section{Conclusion}

Chinese culture has a long history, which is often argued to possess distinctive characteristics. On the other hand, Chinese writing is character based whereas English writing is alphabet based. Exploring Chinese interpersonal communication, particularly in written and digital modes, can not only shed light on the applicability of English- based findings, both linguistically and culturally, to non-English contexts, but also help us better understand the complex relationship between generality and specificity (Ren 2018a) in the (im)politeness and pragmatics research. However, even in the three thematic issues on emancipatory pragmatics in Journal of Pragmatics, Chinese is barely touched upon. This is ironic, as the key notion in (im)politeness research, face, is borrowed from the Chinese culture. The contributions in the present special issue investigating Chinese data will advance our understanding of the (im)politeness practice and provide more food for thought to the research field. In this postscript, I have also argued that it is just the beginning to liberate pragmatics with more nonEnglish data and concepts, but it is definitely not the end. The field needs to explore further the issue of generality and specificity in (im)politeness practice, with various types of data sources. Furthermore, it is crucial for the field to disseminate the research findings to feedback the society and simultaneously benefit from the changes research may make in the society. 


\section{Acknowledgements}

I would like to thank Prof. Dániel Z. Kádár, the special issue editor, for inviting me to write the postscript commentary. I am also grateful to the anonymous reviewers who offered very helpful comments. All remaining errors are my own.

\section{References}

Bakhtin, Mikhail. M. 1981. The dialogic imagination: Four essays by M. M. Bakhtin. Austin, TX: University of Texas Press.

Barron, Anne. 2017. Variational pragmatics. In Anne Barron, Yueguo Gu and Gerard Steen (eds.) The Routledge handbook of pragmatics. London \& New York: Routledge. 91-104.

Barron, Anne and Klaus P. Schneider 2009. Variational pragmatics: Studying the impact of social factors on language use in interaction. Intercultural Pragmatics 6. 425-442.

Blum-Kulka, Shoshana, Juliane House and Gabriele Kasper (eds.). 1989. Cross-cultural pragmatics: Requests and apologies. Norwood, NJ: Ablex.

Bousfield, Derek. 2008). Impoliteness in interaction. Amsterdam \& Philadelphia: John Benjamins.

Bousfield, Derek. 2018). Face(t)s of self and identity in interaction. Journal of Politeness Research 14. 287-305.

Chang, Wei-lin Melody and Michael Haugh. 2012. 'Face' in Taiwanese business interactions: From emic concepts to emic practices. In Y. Pan and D. Z. Kádár (eds.) Chinese discourse and interaction: Theory and practice. Sheffield: Equinox. 127-151.

Chen, Xinren. 2019. 'Family-culture' and Chinese politeness: An emancipatory pragmatic account. Acta Linguistica Academica 66. 251-270.

Culpeper, Jonathan. 1996. Towards an anatomy of impoliteness. Journal of Pragmatics 25. 349-367.

Culpeper, Jonathan. 2011. Impoliteness: Using language to cause offence. Cambridge: Cambridge University Press.

Culpeper, Jonathan, Leyla Marti, Meilian Mei, Minna Nevala and Schauer, Gila. 2010. Cross-cultural variation in the perception of impoliteness: A study of impoliteness events reported by students in England, China, Finland, Germany, and Turkey. Intercultural Pragmatics 7. 597-624.

Dinkin, Aaron J. 2018. It's no problem to be polite: Apparent-time change in responses to thanks. Journal of Sociolinguistics 22. 190-215.

Dynel, Marta. 2015. The landscape of impoliteness research. Journal of Politeness Research 11. 329-354.

Eelen, Gino. 2001. A critique of politeness theories. Manchester: St. Jerome.

Fukushima, Saeko. 2016. Emic understandings of attentiveness and its related concepts among Japanese. East Asian Pragmatics 1. 181-208.

Hanks, William F. 2012. Modalities of co-participation. Journal of Pragmatics 44. 563-565.

Hanks, William F., Sachiko Ide and Yasuhiro Katagiri. 2009. Towards an emancipatory pragmatics. Journal of Pragmatics 41. 1-9. 
Haugh, Michael. 2016. The role of English as a scientific metalanguage for research in pragamatics: Reflections on the metapragamtics of 'politeness' in Japanese. East Asian Pragmatics 1. 39-71.

He, Ziran and Wei Ren. 2016. Current address behaviour in China. East Asian Pragmatics 1. $163-180$.

Jucker, Andreas H. 2018. Data in pragmatic research. In A. H. Jucker, P. Klaus Schneider and W. Bublitz (eds.) Methods in pragmatics. Berlin \& New York: de Gruyter Mouton. 3-36.

Kádár, Dániel Z. 2019. Introduction: Advancing linguistic politeness theory by using Chinese data. Acta Linguistica Academica 66. 149-164.

Kádár, Dániel Z. and Michael Haugh 2013. Understanding politeness. Cambridge: Cambridge University Press.

Kádár, Dániel Z. and Puyu Ning. 2019. Ritual public humiliation: A case study of the applicability of pragmatics to model aggression. Acta Linguistica Academica 66. 189-208.

Kádár, Dániel Z. and Sen Zhang. 2019. (Im)politeness and alignment: A case study of public political monologues. Acta Linguistica Academica 66. 229-250.

Kim, Myung-Hee. 2014. Why self-deprecating? Achieving 'oneness' in conversation. Journal of Pragmatics 69. 82-98.

Lin, Chih-Ying, Helen Woodfield and Wei Ren. 2012. Compliments in Taiwan and Mainland Chinese: The influence of region and compliment topic. Journal of Pragmatics 44. $1486-1502$.

Lee, Cher Leng. 2019. Classical Chinese pronouns: Pragmatic implications and politeness. Acta Linguistica Academica 66. 271-288.

Liu, Fengguang and Wenrui Shi. 2019. Political 'advice' in Chinese public discourse(s). Acta Linguistica Academica 66. 209-228.

Locher, Miriam A. and Richard J. Watts. 2005. Politeness theory and relational work. Journal of Politeness Research 1. 9-33.

Marsden, Emma, Alison Mackey and Luke Plonsky. 2016. The IRIS repository: Advancing research practice and methodology. In A. Mackey \& E. Marsden (eds.) Advancing methodology and practice: The IRIS repository of instruments for research into second languages. London \& New York: Routledge. 1-21.

Mauranen, Anna. 2006. Signaling and preventing misunderstanding in English as a lingua franca communication. International Journal of the Sociology of Language 177. $123-150$.

Mey, Jacob. 2012. Anticipatory pragmatics. Journal of Pragmatics 44. 705-708.

Mills, Sara. 2003. Gender and Politeness. Cambridge: Cambridge University Press.

Page, Ruth. 2014. Saying 'sorry': Corporate apologies posted on Twitter. Journal of Pragmatics 62. 30-45.

Panpothong, Natthaporn and Siriporn Phakdeephasook. 2014. The wide use of mai-pen-rai 'it's not substantial' in Thai interactions and its relationship to the Buddhist concept of Tri Laksana. Journal of Pragmatics 69. 99-107.

Ren, Wei. 2016. Strategies used in Chinese university students' ELF emails to remedy or prevent problems in understanding. In Y.-Sh. Chen, D-H. V. Rau and G. Rau (eds.) Email discourse among Chinese using English as a lingua franca. Berlin: Springer. $163-181$. 
Ren, Wei. 2018a. Exploring Chinese digital communication. Discourse, Context and Media 26. $1-4$.

Ren, Wei. 2018b. Pragmatic strategies to solve and preempt understanding problems in Chinese professionals' emails when using English as lingua franca communication. International Journal of Bilingual Education and Bilingualism 21. 968-981.

Ren, Wei. 2018c. Variational pragmatics in Chinese requests. Wai Guo Yu 41. 66-75.

Ren, Wei, Chih-Ying Lin and Helen Woodfield. 2013. Variational pragmatics in Chinese: Some insights from an empirical study. In I. Kecskés and J. Romero-Trillo (eds.) Research trends in intercultural pragmatics. Berlin \& New York: Mouton de Gruyter. 283-314.

Schneider, Klaus P. and Anne Barron. 2008. Variational pragmatics: A focus on regional varieties in pluricentric languages. Amsterdam \& Philadelphia: John Benjamins.

Spencer-Oatey, Helen and Dániel Z. Kádár. 2016. The bases of (im)politeness evaluations: Culture, the moral order and the East-West debate. East Asian Pragmatics 1. 73-106.

Thomas, Jenny. 1983. Cross-cultural pragmatic failure. Applied Linguistics 4. 91-112.

Watts, Richard. 2003. Politeness. Cambridge: Cambridge University Press.

Watts, Richard. 2005. Linguistic politeness research: Quo vadis? In R. Watts, S. Ide and K. Ehlich (eds.) Politeness in language. Studies in its history, theory and practice (2nd ed.). Berlin \& New York: Mouton de Gruyter. xi-xlvii.

Zhu, Weiha. 2019. The practice and perception of unexpected topic switching in Mandarin Chinese. Acta Linguistica Academica 66. 165-188. 